\title{
Avaliação do processo de Gamificação acerca do tema Direitos Humanos
}

\author{
Cíntia Pereira Dozono de Almeida ${ }^{1}$, Leandra Mendes do Vale ${ }^{1}$, Lucille Garcia \\ Gomes $^{1}$ e Rejane Cristina Rubio Rodrigues da Cunha ${ }^{1}$ \\ ${ }^{1}$ Instituto Master de Ensino Presidente Antônio Carlos de Araguari (IMEPAC) \\ Araguari - MG - Brasil \\ cintia.dozonodimepac.edu.br, leandramvalelgmail.com, \\ lucille.gomesdimepac.edu.br, rejanerubiodimepac.edu.br,
}

\begin{abstract}
This article presents and proposes a model for the implementation and evaluation of the gamification process on the subject of Human Rights as part of the teaching-learning process of students from the Bachelor course in Law in an institution of higher education. The methodology involved the deployment strategy of gamification and consisted of a questionnaire based on the Kirkpatrick training evaluation, the ARCS model and Bloom's taxonomy to collect data on the perception of students. It is expected that this example will bring inspiration to teachers in the selection and use of gamification as part of the educational process.
\end{abstract}

Resumo. Este artigo apresenta e propõe um modelo para a implantação e avaliação do processo de gamificação acerca do tema: Direitos Humanos, como parte integrante do processo de ensino-aprendizagem de discentes do curso de Bacharelado em Direito em uma Instituição de Ensino Superior. A metodologia envolveu a estratégia de implantação da gamificação e consistiu em um questionário baseado na avaliação de treinamento de Kirkpatrick, no modelo ARCS e na taxonomia de Bloom para a coleta de dados sobre a percepção dos alunos. Espera-se que este exemplo possa trazer inspirações a docentes na seleção e uso da gamificação como parte do processo educacional.

\section{Introdução}

O uso de jogos como parte do processo de ensino-aprendizagem não é algo novo, mas tem se tornado alvo de debates entre os educadores, principalmente os que vislumbram as metodologias ativas, além de ser uma das tendências em educação do século XXI. Conforme o site Porvir, curador de conteúdos inovadores sobre estratégias de melhoria da qualidade na educação em âmbito nacional e internacional, a gamificação "é a integração dos elementos dos jogos, como níveis, badges e competição, ao currículo." (PORVIR, 2015).

Admite-se, aqui, a ideia do jogo não mais como associada àquelas de diversão, distração, o lúdico pelo lúdico, mas sim como jogos pedagógicos que têm como objetivos: impor limites e regras; desenvolver a autoconfiança; ampliar a concentração e o raciocínio lógico; estimular a criatividade e a afetividade; conduzir à construção do conhecimento e à aprendizagem significativa. (SILVA; LEVANDOSKI, 2008) 
V Congresso Brasileiro de Informática na Educação (CBIE 2016)

Anais do XXII Workshop de Informática na Escola (WIE 2016)

[...] gamificação se apresenta como um fenômeno emergente com muitas potencialidades de aplicação em diversos campos da atividade humana, pois a linguagem e metodologia dos games são bastante populares, eficazes na resolução de problemas (pelo menos nos mundos virtuais) e aceitas naturalmente pelas atuais gerações que cresceram interagindo com esse tipo de entretenimento. Ou seja, a gamificação se justifica a partir de uma perspectiva sociocultural. (FARDO, 2013, p. 03)

Alguns estudos apontam que o uso da gamificação tem impulsionado a aprendizagem em algumas universidades (KESSLER, 2010). Coletânea organizada por Fadel et al (2014) apresenta diversas definições, propostas de aplicação, questionamentos e soluções ligadas à temática da gamificação aplicada à educação.

Outra importante contribuição nos estudos relacionados a gamificação aplicada a educação foi proposta por Borges et al (2013), os quais realizaram um mapeamento sistemático, analisando 357 artigos publicados sobre a temática, destacando que a maioria dos estudos nesta área são voltados para o ensino superior. Ressaltam, ainda, a perspectiva de análise sobre o engajamento dos alunos para obter e reter a atenção dos mesmos.

Especificamente pensando no ensino superior, dentre as múltiplas possibilidades de temáticas, destaca-se a transversalidade com foco na Educação em Direitos Humanos, que, conforme Resolução do Conselho Nacional de Educação (CNE/ CP no 1/2012) passa a ser de abordagem obrigatória no Projeto Pedagógico dos Cursos de graduação no Brasil.

Assim sendo, escolheu-se o jogo "Diário de Amanhã", desenvolvido pelo Senac São Paulo e pela associação Palas Athena, com selo da UNESCO, o qual tem como objetivo compartilhar os princípios da Declaração Universal dos Direitos Humanos (ONU, 1948). Para tanto o jogo apresenta duas fases: $1^{\mathrm{a}}$ - conteudista; $2^{\mathrm{a}}$ aplicação da realidade, por meio das quais os participantes, em grupos, têm a oportunidade de construir saberes na temática dos Direitos Humanos.

Partindo do pressuposto de que a gamificação é uma tendência em ascensão, dentro dos contextos educacionais e que ainda há poucos relatos de experiência na literatura sobre sua aplicação no ensino superior, este trabalho foi proposto com o objetivo de servir de referência para possíveis outras iniciativas tendo como foco a gamificação.

O contexto de elaboração do presente artigo estruturou-se a partir da estratégia de implantação da gamificação por meio de ações do Núcleo de Inovação e Apoio Pedagógico da IES investigada. A metodologia consistiu na adaptação e aplicação de um questionário baseado na avaliação de treinamento de Kirkpatrick (1994), no modelo ARCS (KELLER, 2009) e na taxonomia de Bloom (1956; CHAPMAN, 2009), segundo estudo proposto por Savi (2010). O foco da coleta de dados foi uma experiência pedagógica de gamificação desenvolvida com 53 alunos do curso de Bacharelado em Direito de uma IES privada, na disciplina de Introdução ao Direito dentro da unidade de aprendizagem acerca do tema "Direitos Humanos". O objetivo deste estudo visa a pontencialização da Motivação, Experiência do Usuário e Conhecimento dos alunos frente ao tema. Toda a avaliação realizada teve como norte permitir ao docente da disciplina e a IES compreender a importância do uso de metodologias baseadas na 
V Congresso Brasileiro de Informática na Educação (CBIE 2016)

Anais do XXII Workshop de Informática na Escola (WIE 2016)

gameficação. Esta é uma abordagem metodológica que tem como principio a investigação-ação.

Este projeto está em fase de divulgação dos resultados, aos outros professores da IES, havendo desde já o interesse em envolver-se com experiências correlatas.

Sendo assim, este registro apresenta-se em 5 tópicos, sendo o primeiro esta Introdução, seguido da descrição de como ocorreu a implantação da estratégia de gamificação na IES. Passa-se ao modelo de avaliação utilizado na metodologia de coleta de dados e a decorrente apresentação dos resultados e discussão. Ao final, as conclusões apontam para as expectativas das autoras de contribuir com pares que também desejem aprimorar sua metodologia de ensino.

\section{Implantação}

A IES possui um Núcleo de Inovação e Apoio Pedagógico, o E-LABORE, que vislumbrou dentro das necessidades institucionais, trabalhar temas atuais e relevantes, principalmente os ligados a metodologias ativas, propondo, portanto, oficinas aos docentes sobre gamificação. Dentre elas, destaca-se a intitulada "O Uso de Jogos em Ambientes Interativos".

A referida atividade prática pretendeu provocar os docentes da IES no sentido da descoberta de outras potencialidades para a construção de aprendizagens efetivas junto aos alunos. O pressuposto é que a articulação de jogos/games e o fazer pedagógico podem tornar a sala de aula um ambiente de construção de conhecimentos mais significativos. Ao mesmo tempo compatibilizou a transversalização do tema "Educação em Direitos Humanos" como um compromisso com a formação de agentes individuais e sociais protagonistas da sua própria e fundamentada cidadania.

Com o intuito de confirmar os propósitos pretendidos com a oferta da atividade prática, foram disponibilizados ao final formulários de avaliação para que fossem preenchidos pelos professores participantes. Os resultados foram tabulados e registrados em gráficos, os quais confirmaram as expectativas dos organizadores. Dentre outros, destacam-se os seguintes depoimentos:

"Momentos como esse nos incentivam em nossa missão de ensinar".

"Temas atuais e relevantes estão sendo trabalhados. Um avanço pedagógico".

"Parabéns! Interessante e prático, acrescentou múltiplas ideias ao corpo docente".

Após aplicação da oficina, que aconteceu no dia 27 de abril de 2016, vários professores se interessaram pelo tema sendo que um, do curso de Direito, fez uma proposta de aplicar aos alunos do $1^{\circ}$ período, na disciplina de Introdução ao Direito, o Jogo "Diário de Amanhã", tal como foi desenvolvida pelo E-LABORE na oficina destinada aos professores.

A estratégia utilizada pelo referido docente foi realizar uma pré-aula introduzindo o tema "Direitos Humanos" por meio da apresentação da Declaração Universal dos Direitos Humanos; posteriormente, na aula seguinte ocorrida em meados de maio, convidou a turma para participar da gamificação. 
V Congresso Brasileiro de Informática na Educação (CBIE 2016)

Anais do XXII Workshop de Informática na Escola (WIE 2016)

\section{Modelo de Avaliação}

O modelo de avaliação de jogos proposto no estudo de Savi (2010) aponta o uso do nível 1 do modelo de avaliação de treinamento de Kirkpatrick (1994), para avaliar o uso da gamificação nas relações entre os alunos. Este mesmo estudo também propõe o uso do modelo ARCS [KELLER, 2009] para avaliar e apontar o nível de motivação dos alunos ao usarem jogos, além da taxonomia de Bloom [BLOOM, 1956; CHAPMAN, 2009] como apoio na avaliação do impacto da aprendizagem.

Partindo da proposta inicial de Savi (2010), viu-se a necessidade de testar alguns aspectos da metodologia de avaliação proposta, analisando a percepção dos alunos também em relação aos aspectos: Motivação, Experiência do Usuário e Conhecimento. No trabalho de Savi (2010), o questionário proposto foi apresentado aos alunos na forma de afirmações para que indicassem seu grau de concordância em uma escala Likert de 7 pontos, variando de "discordo totalmente" até "concordo totalmente". Desta forma, adaptou-se o questionário de Savi (2010), como apresentado na Figura 1, no qual foram propostas, dentro do escopo de avaliação, as mesmas afirmações, só que desta vez, para que os alunos pudessem escolher, dentre as opções propostas, a(s) que(ais) tivesse(m) o maior grau de relevância dentro da experiência vivida por eles no processo de gamificação. Esta adaptação se justifica pelo fato de a IES estar em um programa de aplicação da gamificação e visa descobrir, dentre as afirmações disponibilizadas, as que mais dão significado ao critério avaliado dentre os quesitos Motivação, Experiência do Usuário e Conhecimento. Tais análises servirão de subsídio para publicações futuras.

\begin{tabular}{|c|c|}
\hline \multicolumn{2}{|c|}{$\begin{array}{l}\text { QUESTIONÁRIO AVALIAÇÃO - GAMIFICAÇÃO - 11/05/2016 } \\
\text { Marque a(s) alternativa(s) que melhor representa a sua percepção em relação ao jogo }\end{array}$} \\
\hline \multicolumn{2}{|c|}{ INFORMAÇÕES PESSOAIS } \\
\hline Sexo: ( ) Masculino ( ) Feminino & Idade: \\
\hline \multicolumn{2}{|c|}{$\begin{array}{l}\text { Durante seus anos na escola, foi utilizado algum tipo de jogo educativo (gamificação) para facilitar o seu aprendizado? } \\
\text { ( ) } \operatorname{sim}(\text { ) Não }\end{array}$} \\
\hline \multicolumn{2}{|c|}{ MOTIVAÇÃO } \\
\hline \multicolumn{2}{|l|}{ Com relação ao critério: Atenção } \\
\hline \multicolumn{2}{|l|}{$\begin{array}{l}\text { ( ) Houve algo interessante no início do jogo que capturou minha atenção. } \\
\text { ( ) O design da interface do jogo é atraente. }\end{array}$} \\
\hline \multicolumn{2}{|l|}{ Com relação ao critério: Relevância } \\
\hline \multicolumn{2}{|l|}{$\begin{array}{l}\text { ( ) Ficou claro para mim como o conteúdo do jogo está relacionado com coisas qu } \\
\text { ( ) Eu gostei tanto do jogo que gostaria de aprender mais sobre o assunto abord } \\
\text { ( ) O conteúdo do jogo é relevante para meus interesses. } \\
\text { ( ) Eu poderia relacionar o conteúdo do jogo com coisas que já vi, fiz ou pensei. } \\
\text { ( ) O conteúdo do jogo será útil para mim. }\end{array}$} \\
\hline \multicolumn{2}{|l|}{ Com relação ao critério: Confiança } \\
\hline \multicolumn{2}{|l|}{$\begin{array}{l}\text { ( ) O jogo foi mais difícil de entender do que eu gostaria. } \\
\text { ( ) O jogo tinha tanta informação que foi difícil identificar e lembrar dos } \\
\text { ( ) O conteúdo do jogo é tão abstrato que foi difícil manter a atenção ne } \\
\text { ( ) As atividades do jogo foram muito difíceis. } \\
\text { ( ) Eu não consegui entender uma boa parcela do material do jogo. }\end{array}$} \\
\hline \multicolumn{2}{|l|}{ Com relação ao critério: Satisfação } \\
\hline \multicolumn{2}{|c|}{$\begin{array}{l}\text { ( ) Completar os exercícios do jogo me deu um sentimento de realização. } \\
\text { ( ) Eu aprendi algumas coisas com o jogo que foram surpreendentes ou inesperadas. } \\
\text { ( ) Os textos de feedback depois dos exercícios, ou outros comentário do jogo, me ajudaram a sentir recompensado pelo } \\
\text { meu esforço. } \\
\text { ( ) Eu me senti bem ao completar o jogo. }\end{array}$} \\
\hline \multicolumn{2}{|c|}{ EXPERIÊNCIA DO USUÁRIO } \\
\hline \multicolumn{2}{|l|}{ Com relação ao critério: Imersão } \\
\hline $\begin{array}{l}\text { ( ) Eu não percebi o tempo passar enquanto jogava. } \\
\text { ( ) Eu perdi a consciência do que estava ao meu redor enquanto jogava. } \\
\text { ( ) Me senti mais no ambiente do jogo do que no mundo real. }\end{array}$ & \\
\hline
\end{tabular}


V Congresso Brasileiro de Informática na Educação (CBIE 2016)

Anais do XXII Workshop de Informática na Escola (WIE 2016)

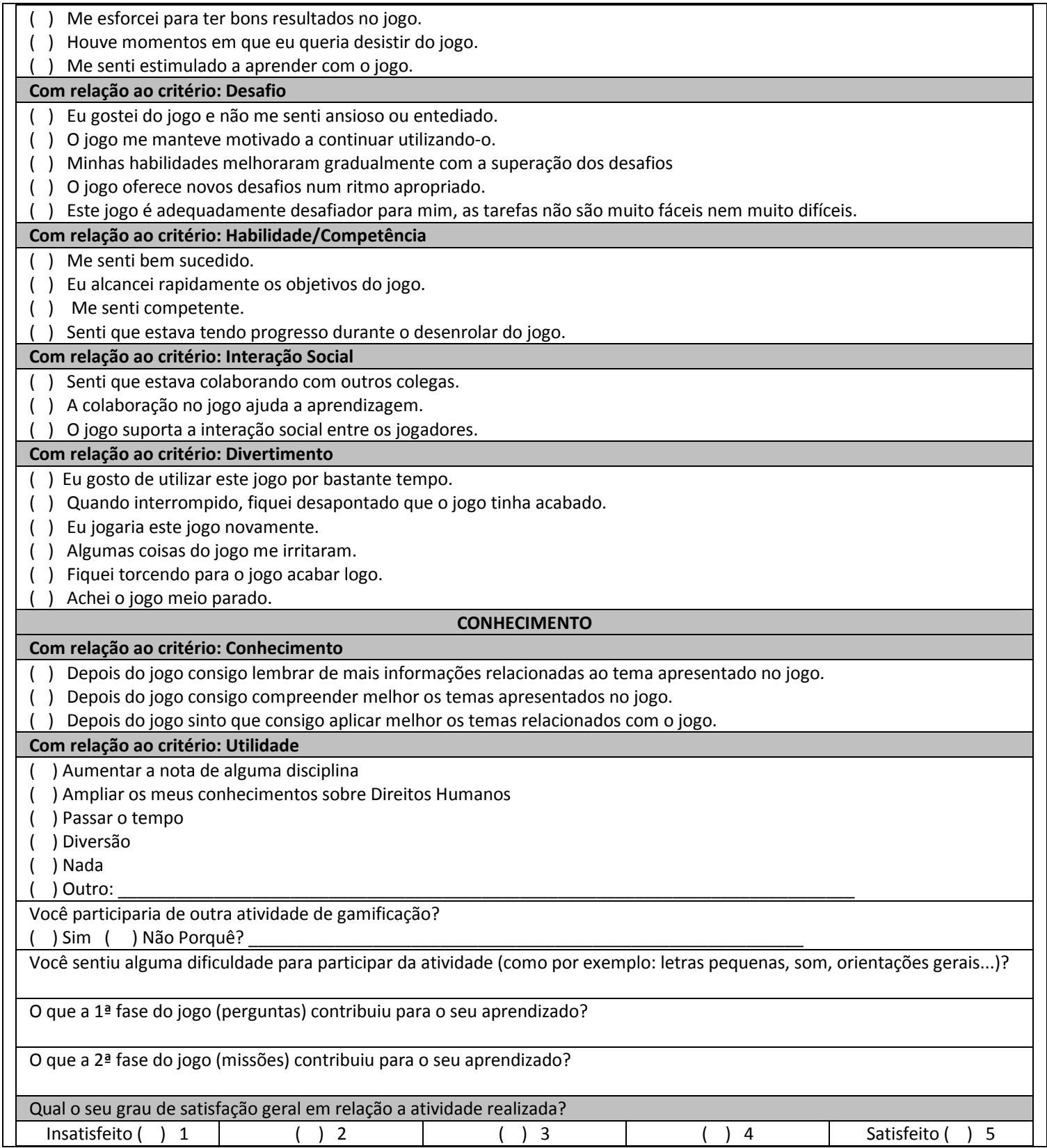

Figura 1. Questionário de avaliação da aplicação do jogo

\section{Resultados e Discussão}

Depois de coletado os dados por intermédio do questionário observa-se a contribuição significativa que o jogo proporcionou aos alunos no que se refere aos critérios avaliados: Motivação, Experiência do Usuário e Conhecimento.

Participaram da atividade 53 alunos do $1^{\circ}$ período do Curso de Direito da Instituição, regularmente matriculados na disciplina de Introdução ao Direito, sendo 23 do sexo masculino e 30 do feminino. Destes, 35 estão na faixa etária de 17 a 24 anos, 10 entre 25 e 32 anos e o restante acima de 33 anos. Do total de participantes, 54\% nunca participaram de atividades que envolvessem jogos em sala de aula. 
V Congresso Brasileiro de Informática na Educação (CBIE 2016)

Anais do XXII Workshop de Informática na Escola (WIE 2016)

No critério, "Motivação", Figura 2, percebeu-se que o jogo escolhido tem um design atraente $(67,92 \%)$, que os alunos julgam como útil o conteúdo apresentado $(35,85 \%)$, e isso lhes instigou a pesquisar mais sobre o tema: "Direitos Humanos" $(35,85 \%)$, dando a eles uma sensação de bem estar ao concluir o jogo - sentimento de realização $(37,74 \%)$. Já outros $(32,08 \%)$ julgaram que o jogo tinha tanta informação que foi difícil identificar e lembrar dos pontos importantes sobre o tema.

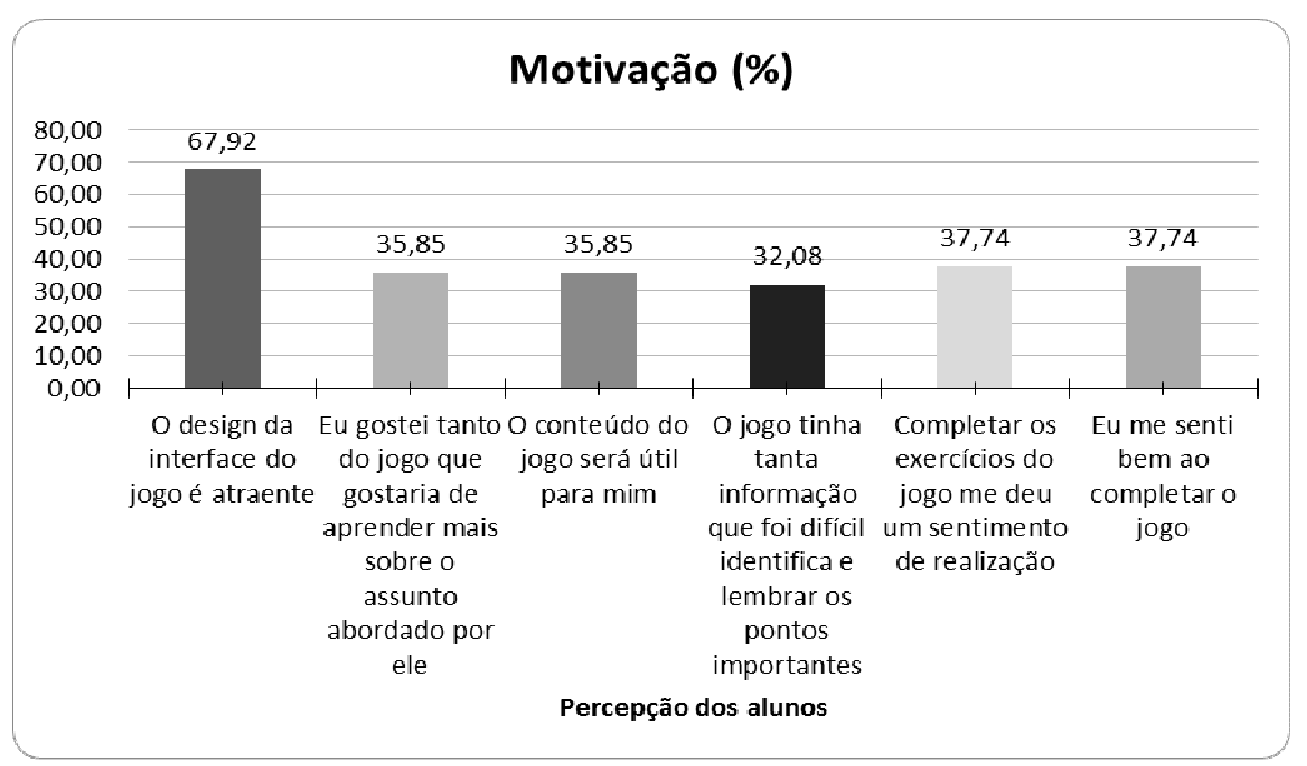

Figura 2. Resultados da avaliação da aplicação do jogo: Critério: Motivação

No critério "Experiência do Usuário", Figura 3, o jogo demonstrou não ser cansativo, pois os alunos não perceberam o tempo passar $(58,49 \%)$, enfatizando a importância da colaboração no processo de aprendizagem $(50,94 \%)$, além do sentimento de progresso durante o desenrolar do jogo $(54,72 \%)$.

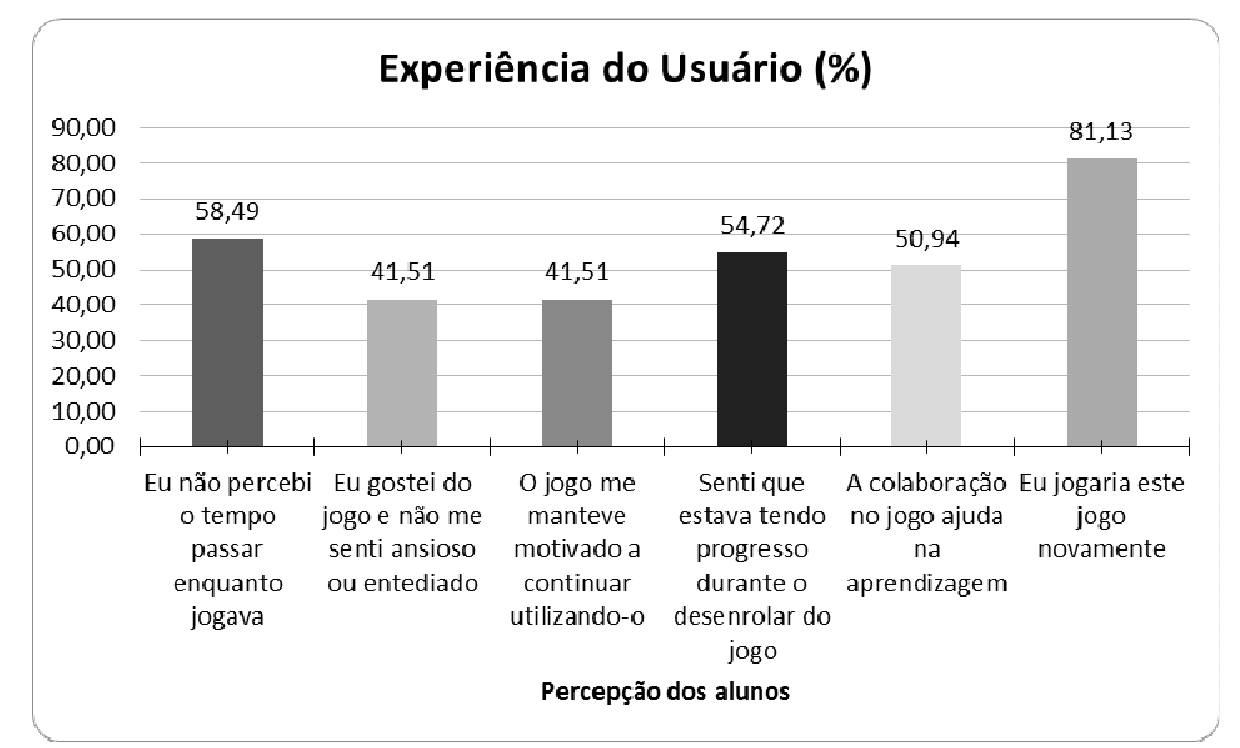

Figura 3. Resultados da avaliação da aplicação do jogo: Critério: Experiência do Usuário 
No critério, "Conhecimento", Figura 4, o jogo provou que os alunos conseguem compreender melhor os temas apresentados no jogo após a atividade $(64,15 \%)$ e que seus conhecimentos acerca de "Direitos Humanos" foram ampliados (92,45\%). E a grande maioria $(94,2 \%)$ participaria novamente de atividade semelhante, demonstrando satisfação em relação à mesma.

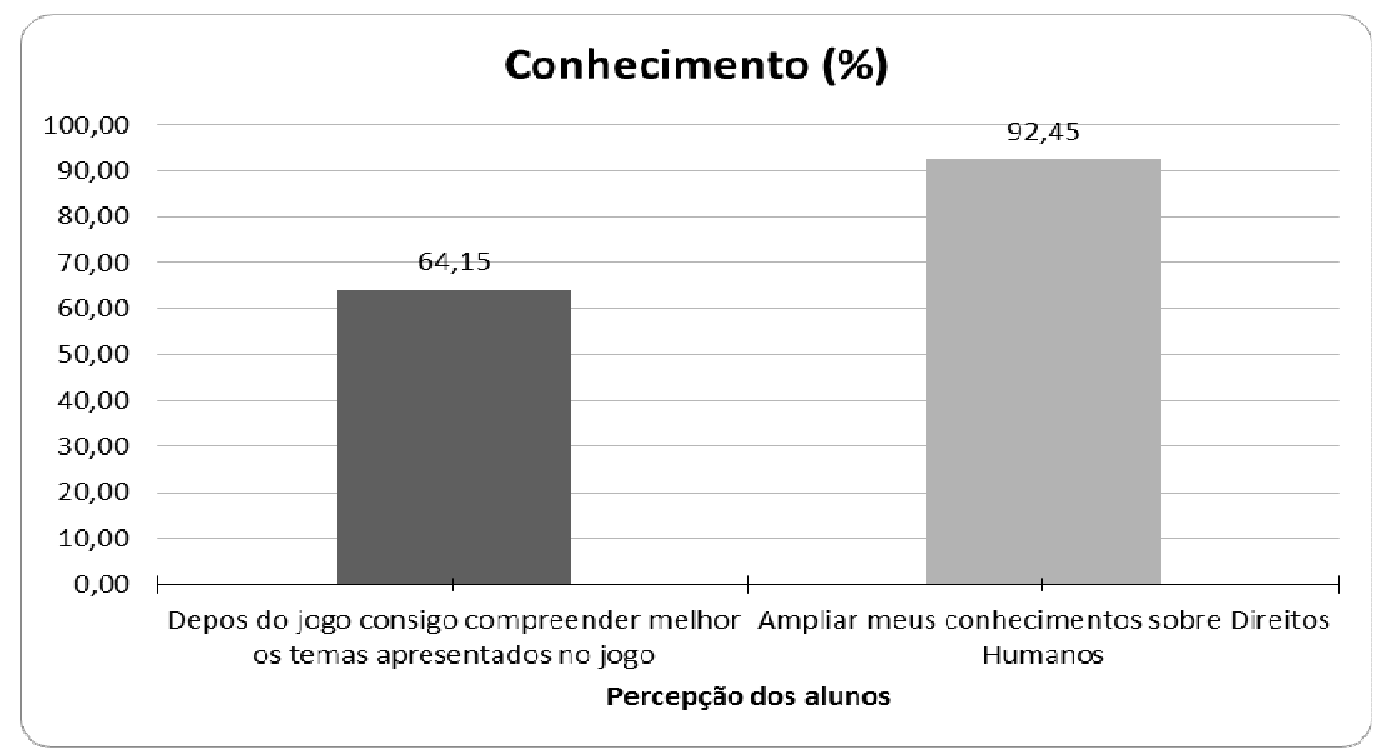

Figura 4. Resultados da avaliação da aplicação do jogo: Critério: Conhecimento

Considerando estes resultados, pode-se concluir que a gamificação assume condição de fenômeno que ganha visibilidade diante de sua capacidade de criação de novas experiências e posturas, no contexto acadêmico. Ao participar do mundo do entretenimento digital, o aluno do ensino superior vê-se incentivado pelas diversas possibilidades que podem ser exploradas por meio dos jogos digitais e seu impacto na sociedade contemporânea, ainda, transversalizando o tema em "Direitos Humanos".

\section{Conclusões}

Espera-se que este artigo possa trazer contribuições relevantes a professores que anseiem por mudanças em suas metodologias, em especial no ensino superior, que é o foco de análise do presente trabalho. Além de reforçar a ideia de Savi (2010) da importância de um modelo de avaliação de jogos educacionais que busquem identificar a Motivação, a Experiência do Usuário e o Conhecimento, dentro de um contexto educacional. No mesmo sentido em que se configuram os resultados atingidos por meio do trabalho de Lopes, Toda e Brancher (2015, p.167): "Os jogos digitais desenvolvidos contém motivadores intrínsecos e extrínsecos, que permitem ao jogador se divertir enquanto aprende, a partir da interação com o mundo virtual".

Norteados pelos pressupostos de que a gamificação potencializa o trabalho pedagógico de construção do conhecimento, ainda, considerando os elementos intrínsecos e extrínsecos presentes no processo, é possível afirmar que os jogos podem 
V Congresso Brasileiro de Informática na Educação (CBIE 2016)

Anais do XXII Workshop de Informática na Escola (WIE 2016)

contribuir para o êxito de um trabalho docente, que privilegie a formação de sujeitos individuais e sociais capazes de edificar a própria cidadania.

\section{Referências}

BLOOM, B.S. Taxonomy of educational objectives: The classification of educational goals: Handbook I, cognitive domain. New York; Toronto: Longmans, Green. 1956. $207 \mathrm{p}$.

BORGES, Simone de S. et al. Gamificação Aplicada à Educação: Um Mapeamento Sistemático. In: Anais do Simpósio Brasileiro de Informática na Educação. 2013. p. 234.

CHAPMAN, A. Kirkpatrick's learning and training evaluation theory. Businessballs, 2009. Disponível em:

$<$ http://www.businessballs.com/kirkpatricklearningevaluationmodel.htm $>$. Acesso em: mai. 2016.

FADEL, L.M. et al. Gamificação na Educação. São Paulo: Pimenta Cultural, 2014.

FARDO, M. L. A gamificação aplicada em ambientes de aprendizagem. RENOTE, v. 11, n. 1, 2013.

KELLER, J. M. Motivational Design for Learning and Performance: The ARCS Model Approach. Springer, 2009.

KESSLER, M. C. et al. Impulsionando a aprendizagem na universidade por meio de jogos educativos digitais. Simpósio Brasileiro de Informática na Educação, v. 21, 2010 .

KIRKPATRICK, D. L. Evaluating Training Programs - The Four Levels. BerrettKoehler Publishers, Inc. 1994.

LOPES, Ronan Anacleto; TODA, Armando Maciel; BRANCHER, Jacques Dúlio. Um estudo preliminar sobre conceitos extrínsecos e intrínsecos do processo de Gamification. Revista Brasileira de Informática na Educação, v. 23, n. 03, p. 164, 2015.

ORGANIZAÇÃO DAS NAÇÕES UNIDAS. Declaração Universal dos Direitos

Humanos. 1948. Disponível em: < http://www.onu-brasil.org.br/documentos_ direitoshumanos.php > Acesso em: 05 jun. 2016.

PORVIR. Gamificação. Glossário. [site] 25 ago. 2014. Disponível em: < http://porvir.org/gamificacao/ > Acesso em: 04 jun. 2016.

SAVI, R. et al. Proposta de um modelo de avaliação de jogos educacionais. RENOTE, v. 8, n. 3, 2010.

SILVA, K. C. O.; LEVANDOSKI, A. A. O Jogo como Estratégia no Processo EnsinoAprendizagem de Matemática na $6^{\mathrm{a}}$ Série ou $7^{\circ}$ Ano, 2008. Disponível em: < http://www.diaadiaeducacao.pr.gov.br/portals/pde/arquivos/1665-8.pdf $>$ Acesso em: 15 abr. 2016.) 